WORK-FAMILY CONFLICT, ACCULTURATION, AND WELL-BEING

Mechanisms Linking Acculturation, Work-family conflict, and Subjective Wellbeing among Chinese immigrants in New Zealand

\author{
Sudong Shang* \\ School of Psychology, University of Waikato, New Zealand \\ Michael P. O’Driscoll \\ School of Psychology, University of Waikato, New Zealand \\ and \\ Maree Roche \\ School of Psychology, University of Waikato, New Zealand
}

*Correspondence concerning this article should be addressed to: Sudong Shang, School of Psychology, University of Waikato, Private Bag 3105, Hamilton 3240, New

Zealand. Email: ss447@,students.waikato.ac.nz / sudongshang@gmail.com.

Telephone: +64 78384032 extn. 8040; Fax: +64 78585132 .

Please cite this article as:

Shang, S., O'Driscoll, M. P., \& Roche, M. (In press). Mechanisms linking acculturation, work-family conflict, and subjective well-being among Chinese immigrants in New Zealand. Human Resource Management. DOI:

10.1002/hrm.21890. 
WORK-FAMILY CONFLICT, ACCULTURATION, AND WELL-BEING

\begin{abstract}
Work-family conflict (WFC) research has focused almost exclusively on nonimmigrant populations. To expand the understanding of WFC among immigrants, this longitudinal study (6-month time lag) aimed to investigate the mechanisms linking acculturation, strain-based WFC, and subjective well-being. In order to do this, two theory-based mediation models were developed and tested on a sample of 264 Chinese immigrants working in New Zealand using structural equation modeling. Results show that subjective well-being mediated the effect of acculturation on strainbased WFC, and acculturation did not directly influence strain-based WFC.

Furthermore, evidence was found for reciprocal relationships between strain-based WFC and subjective well-being, as well as for the same-domain perspective. Strainbased work interfering with family and strain-based family interfering with work (two directions of strain-based WFC) have significant effects on work-related and familyrelated well-being respectively, and vice versa. Overall, the present study provides an appropriate platform for future work-family research on immigrant populations, and offers practical prescriptions for human resource managers to operate successfully within a diverse workplace.
\end{abstract}

Keywords: work-family conflict, Chinese immigrants in New Zealand, acculturation, mediation, subjective well-being 
WORK-FAMILY CONFLICT, ACCULTURATION, AND WELL-BEING

\section{Mechanisms Linking Acculturation, Work-family conflict, and Subjective Well-being among Chinese Immigrants in New Zealand}

\section{Introduction}

Although work-family issues have been widely researched in many countries over the past 30 years, organizations are still confronting the challenge of a changing global reality, including frequently increasing migration. Immigrants are exposed to a new culture which may be very different from their home cultures, and working environments are even more diverse. Most previous work-family studies assume that individuals function only within their own cultures, and overlook the impacts of acculturation. Acculturation generally refers to the process of immigrants adapting to a new culture (Berry, 2002). Prior research has suggested that individuals influenced by different cultures may have different work-family experiences (e.g., Aycan, 2008; Powell, Francesco, \& Ling, 2009). Therefore, the work-family experiences of immigrants, who are always juggling their home and host cultures (Li, 2011), may be more complex than non-immigrants.

Acculturation is an inevitable journey for immigrants, and can exert a considerable impact on their work, family and even subjective well-being (SuárezOrozco \& Suárez-Orozco, 2010). Grzywacz et al. (2007) stated that acculturation might play a critical role when work-family theories are applied to immigrant populations, but only recently has the role of acculturation received the attention of work-family researchers. Olson, Huffman, Leiva, and Culbertson (2013) found that social-based acculturation but not language-based acculturation could directly contribute to WFC, which provided some insight into the role of acculturation in work-family experiences among immigrants. However, social-based acculturation 
WORK-FAMILY CONFLICT, ACCULTURATION, AND WELL-BEING

may transfer its impact to WFC through subjective well-being, since the levels of acculturation could influence individuals' subjective well-being (Suárez-Orozco \& Suárez-Orozco, 2010) and subjective well-being could directly affect their WFC (e.g., Nohe, Meier, Sonntag, \& Michel, 2015). Additionally, the relationship between subjective well-being and WFC in the context of acculturation has not been discussed by Olson et al. (2013). Furthermore, besides language- and social-based acculturation, acculturation includes more components, such as food consumption and social identity (e.g., Gim Chung, Kim, \& Abreu, 2004). Therefore, the mechanisms linking acculturation with WFC and subjective well-being are still obscure. A lack of understanding of WFC among immigrants may constrain organizations from proactively facilitating employees' subjective well-being in a diverse working environment.

To address this issue, the main aim of the current research is to shed light upon how immigrants' acculturation, work-family conflict experiences and subjective wellbeing interact with each other. In particular, this study utilized a longitudinal design (two waves) which aids in addressing possible causal connections, as this longitudinal design could reflect the dynamic process of acculturation (Olson et al., 2013) and of work-family conflict (Odle-Dusseau et al., 2013). This research focused on Chinese immigrants in New Zealand, who are becoming a crucial segment of the current and future workforce (Badkar \& Tuya, 2010).

The present research examines work-family experiences among immigrant populations, thereby encouraging future work-family research to better understand complex WFC experiences among them. Practically, this work offers some beneficial prescriptions for organizations on how to manage work-family conflict in a diverse working environment, including aiming to improve their work-family policies and 
WORK-FAMILY CONFLICT, ACCULTURATION, AND WELL-BEING

practices. This may ensure the needs of immigrants in a diverse working environment can be met, and at the same time foster the organizational success (Grzywacz et al., 2007).

\section{Work-Family Conflict, Acculturation and Subjective Well-being}

Work-family conflict. Work-family conflict (WFC) is "a form of inter-role conflict in which the role pressures from the work and family domains are mutually incompatible in some respect. That is, participation in the family (work) role is made more difficult by virtue of participation in the work (family) role" (Greenhaus \& Beutell, 1985, p. 77). Based on the sources of inter-role conflict, WFC has generally been regarded as three major forms: time-based conflict, strain-based conflict, and behaviour-based conflict (Geenhaus \& Beutell, 1985). However, this study only focuses on strain-based conflict because of the following reasons. Firstly, Shang, O'Driscoll, and Roche (2017) suggested that there was little relationship between time-based WFC and well-being among Chinese immigrants. That is because modern technologies and the popularity of flexible time arrangement could provide opportunities for them to manage time-based WFC, and immigrants are likely to sacrifice their time to achieve their work and family demands and may not regard time-based conflict as a problem. Therefore, time-based WFC was not included in this study. Second, behaviour-based conflict was also not discussed in the present study, as it usually happens among individuals with very unique occupations. For example, correctional staff at work may have developed behaviours which are not necessarily appropriate in family life, such as questioning family members or barking orders (Lambert, Hogan, Camp, \& Ventura, 2006). Except for these unique occupations, appropriate behaviours at work (home) may not be greatly incompatible with appropriate behaviours at home (work). 
In sum, only strain-based conflict is focused on in this paper, and this conflict suggests that psychological strain experienced in one role intrudes into and interferes with participation in another role (Geenhaus \& Beutell, 1985). According to the definition, WFC is a bidirectional concept: work interference with family (WIF) and family interference with work (FIW) (e.g., Byron, 2005). Thus, two types of WFC are discussed in this paper: strain-based WIF, and strain-based FIW. In the following paper, the acronyms, WIF and FIW, refer to strain-based WIF and strain-based FIW respectively, while WFC refers to strain-based WFC, if there is no specific indication.

Acculturation. Acculturation is a complex process where immigrants adjust and adapt to a new culture and society, when they have moved to a new country (Sonderegger \& Barrett, 2004). During this process, immigrants deliberately or accidentally learn host cultural features, including language, clothing, food consumption, cultural knowledge, and values, and then adjust their behaviours, identity and values to align with the host cultures (Berry, 2002). However, this process is not easy. The larger the cultural distance (the degree of dissimilarity between two cultures), the more difficult it is for immigrants to adapt (Hofstede, Hofstede, \& Minkov, 2010). This is the case of Chinese immigrants who were born in a collectivistic culture, but now are living in a predominantly individualistic culture of New Zealand (Hofstede et al., 2010). This study concentrates only on one cultural dimension, individualism versus collectivism, because this dimension is the most commonly applied construct to interpret cultural differences (e.g., Fischer et al., 2009; Hofstede et al., 2010), and has relatively high influence on the work-family interface (e.g., Francesco \& Gold, 2005; Powell et al., 2009).

Subjective well-being. Subjective well-being is defined as “a person's cognitive and affective evaluations of his or her life" (Diener, Lucas, \& Oishi, 2004, 
p. 63). It is a very broad concept, and can be indicated by positive emotion, psychological strain, depression, family satisfaction, job satisfaction, and life satisfaction (e.g., Ford, Heinen, \& Langkamer, 2007). Bellavia and Frone (2005) suggested that subjective well-being related to WFC can be divided into three categories: work-related well-being which primarily concerns the work, familyrelated well-being which primarily concerns the family, and individual well-being which primarily concerns the individual. Therefore, this research focuses on the following three indicators to represent the three categories. Job satisfaction refers to the degree to which an individual is satisfied or happy with his/her job (e.g., Carlson, Kacmar, \& Williams, 2000). Family satisfaction refers to the degree to which an individual is satisfied or happy with his/her family (e.g., Carlson et al., 2000). Psychological health (the reverse is psychological strain) describes an individual's general feeling of emotional satisfaction (Kalliath, O'Driscoll, \& Brough, 2004).

\section{Mechanisms Linking WFC, Acculturation and Subjective Well-being}

As mentioned before, the relationships among WFC, acculturation and subjective well-being remain unclear. To give some insight into these relationships, we proposed two alternative models: Model A, WFC mediating the relationship between acculturation and subjective well-being (see Figure 1); and Model B, subjective well-being mediating the relationship between acculturation and WFC (see

Figure 2). The two proposed mechanisms could be basically supported by two prominent theoretical paradigms, role theory (Kahn, Wolfe, Quinn, Snoek, \& Rosenthal, 1964) and conservation of resources theory (Hobfoll, 1989, 2011), and some supplemental theories (which will be discussed later). Role theory implies that individuals attempt to meet multiple work and family role expectations, and they may suffer some degree of role pressure, when their work and family roles are ambiguous 
(Kahn et al., 1964). Conservation of resources theory suggests that individuals may experience stress or strain when their personal resources (anything valued by a person, such as attention, energies, time, and personal characteristics) are threatened or actually lost, which will motivate them to seek more resources in order to protect their personal resource pool (Hobfoll, 1989, 2011). The detailed interpretation of the two theories is discussed further in the following sections. Presenting the two competing models would enrich the literature by virtue of extending work-family issues into an immigration context.

\section{INSERT FIGURE 1 AND FIGURE 2 ABOUT HERE}

\section{WFC mediating the effect of acculturation on subjective well-being}

(Model A). In the work-family literature, a dominant "full-range" model contains three main components: antecedents, a mediating WFC construct, and consequences (Michel, Mitchelson, Kotrba, LeBreton, \& Baltes, 2009, p. 201).

According to role theory, various work and family role expectations individuals attempt to meet are one main category of the antecedents of WFC (Judge \& Colquitt, 2004). During the process of acculturation, to fit into the new culture, immigrants have to come to terms with the work-role and family-role expectations which may be very different from their home culture (Lazarova, Westman, \& Shaffer, 2010; Olson et al., 2013). However, the expectations are always implicit, unlike regulations which are clearly written down. Immigrants have to learn expectations from their own experiences or by observing members of the host culture speaking and behaving. Therefore, the information they obtain may lack clarity. For example, at the workplace, when a Chinese immigrant encounters interpersonal conflict, some people 
may advise him/her to keep silent, while some others may suggest him/her to express him/herself (Wang, 2015). In the family life, Chinese immigrant parents may hesitate as to whether they should educate their kids in a normal Chinese way to be "tiger parents" (strict and demanding parents who always push their children to high achievement), or in a general Western way learning freely or through play.

Confronting ambiguous information for their work or family role, immigrants would cognitively weigh the advantages and disadvantages of both Chinese and Western ways to find a solution, which is likely to increase their role pressure (Beehr \& Glazer, 2005; Cooper, Cooper, \& Eaker, 1988). Moreover, according to the conservation of resources theory, the process of weighing could threaten or deplete immigrants' personal finite resources (e.g., attention and energy), which will increase the incompatibility between work and family domains (e.g., Edwards \& Rothbard, 2000; Grandey \& Cropanzano, 1999). In summary, in the process of acculturation, the more ambiguous work/family roles individuals face, the greater psychological expenditure they require for their work/family, resulting in a decrease in available resources for their family/work. In this circumstance, WIF and FIW are likely to happen.

Based on above discussion, enhanced acculturation would enhance the clarity of immigrants' work and family roles. McDougall and Drummond (2010) suggested that role clarity could minimize the psychological expenditure, resulting in people dealing with work and family demands more efficiently. In the circumstances, the likelihood of strain in one role intruding into the other role is minimal. Thus, improved acculturation may help ameliorate both WIF and FIW.

The above proposition could also be supported by a cultural perspective. Much research has revealed that acculturation could happen at the value level (e.g., Berry, 
2002; Pooyan, 1984). That means values of immigrants learned from their home countries may gradually change to be similar to values of locals in the host countries. In the current study, Chinese immigrants moved from a collectivistic culture to a predominantly individualistic culture of New Zealand (Hofstede et al., 2010). The values of Chinese immigrants may be progressively turning from collectivism to individualism through their frequent interaction with locals during their living in New Zealand. In contrast to collectivists generally regarding work and family domains as integrated, individualists are prone to see the two domains as distinct (Spector et al., 2004). The more work and family are mingled, the more liable people experience WFC. Therefore, Spector et al. (2004) and Lu, Gilmour, Kao, and Huang (2006) reported that individualists (e.g., Anglos) had a lower level of WFC than collectivists (e.g., Chinese) through comparison between the two groups. Accordingly, the higher levels of acculturation Chinese immigrants obtain, the more likely they undergo lower levels of WFC. However, some suggest that WFC is minimized for collectivists due to higher levels of social support (Powell et al., 2009), and this may not be the case of Chinese immigrants, because moving to another country would result in a big loss of their social support in their countries of origin.

Given the above arguments, we proposed the following hypothesis:

Hypothesis 1. Acculturation will be negatively related to (a) work interfering with family and (b) family interfering with work.

A substantial body of evidence has demonstrated that when work-family conflict (WFC) happens, there are adverse consequences to individuals' subjective well-being, such as job satisfaction, family satisfaction, and psychological health (e.g., O'Driscoll, Brough, \& Kalliath, 2004). It is because, according to the conservation of resources theory, strain from high levels of WFC is about to tax 
WORK-FAMILY CONFLICT, ACCULTURATION, AND WELL-BEING

personal resources (attention and energy), which thus will lead to decreased subjective well-being (e.g., Dewe, O'Driscoll, \& Cooper, 2010; Hobfoll, 1989). Specifically, much evidence has suggested that both WIF and FIW are strongly positively related to psychological strain (as opposed to psychological health) (e.g., Allen, Herst, Bruck, \& Sutton, 2000; Kinnunen, Feldt, Geurts, \& Pulkkinen, 2006; Shang et al., 2017). Furthermore, Amstad, Meier, Fasel, Elfering, and Semmer (2011) stated that increased WIF and FIW will cause increased levels of anxiety/depression, and social dysfunction, which are major indicators of psychological strain.

Hypothesis 2. (a) Work interfering with family and (b) family interfering with work will be positively related to psychological strain (including: anxiety/depression, and social dysfunction).

Unlike psychological strain, the relationships between WIF/FIW and job/family satisfaction are still debated in the work-family literature. In order to interpret those relationships, the segmentation theory is introduced. The segmentation theory suggests that there are firm boundaries between work and family, which gives rise to two contradictory perspectives: cross-domain perspective and same-domain perspective (which also refers to matching or resource attribution perspective) (e.g., Amstad et al., 2011; Nohe et al., 2015). The cross-domain perspective suggests that WIF negatively impacts on individuals' family satisfaction, whereas FIW negatively influences their job satisfaction. When WIF ( FIW) occurs, it will be difficult for the person to meet demands which family (work) requires, such as investment of attention and energy (Ford et al., 2007). On the other hand, the same-domain perspective suggests that WIF is negatively related to job satisfaction, while FIW is negatively associated with family satisfaction (Amstad et al., 2011). The rationale behind this perspective is that individuals are likely to blame the domain where the conflict arises 
WORK-FAMILY CONFLICT, ACCULTURATION, AND WELL-BEING

rather than the receiving domain, when experiencing work-family conflict (Amstad et al., 2011; Nohe \& Sonntag, 2014).

In addition, boundary-permeability perspective suggests that the boundaries between work and family may be permeable, and work and family domains are more likely to be integrated (Rothbard \& Ramarajan, 2009). As such, WIF and FIW may be related to both job and family satisfaction. Shang et al. (2017) found that WIF and FIW were negatively associated with both job and family satisfaction among Chinese immigrants in New Zealand. The reason is that immigrant family members are highly dependent on each other for support and companionship, as they are isolated from their relatives and friends in their home countries, which enhances the integration of work and family domains (Lazarova et al., 2010). Overall, three perspectives (crossdomain, same-domain, and boundary-permeability perspectives) currently provide insight into the relationships between WIF/FIW and job/family satisfaction. In sum, to determine which perspective is more applicable in a sample of Chinese immigrants, we proposed that:

Hypothesis 3. (a) Work interfering with family and (b) family interfering with work will be negatively related to job satisfaction.

Hypothesis 4. (a) Work interfering with family and (b) family interfering with work will be negatively related to family satisfaction.

The work-family literature suggests that WFC can mediate the relationship of either family or work stressors and commitment with subjective well-being, since those relationships are not direct (Michel, et al., 2009). During the process of acculturation, many immigrants will have to endure the stress and pressure generated from their cultural shock, which may further impose strain on their work and family (Suárez-Orozco \& Suárez-Orozco, 2010). Therefore, acculturation could be regarded 
as a major cause of WIF and FIW. Furthermore, drawing on the conservation of resources theory, high extent of WIF/FIW is bound to impair the sense of their subjective well-being (Michel et al., 2011). In support of our argument, research has reported social-based acculturation to be negatively related to WFC (Olson et al., 2013), and WFC to be negatively associated with family satisfaction, job satisfaction, and psychological health (O'Driscoll et al., 2004). In addition, most research on the mediation role of WFC was conducted among individuals who function solely in their own cultures. What remains unclear and untested is whether WFC acts as a mediator in an immigrant population.

Given the aforementioned arguments (including Hypotheses 1-4), assessing the mediation role of WFC among immigrants may broaden our understanding of the application of work-family theories in diverse ethnic groups. Thus, we predicted that WFC will mediate the relationships between acculturation and subjective well-being.

Hypothesis 5. Work interfering with family will mediate the relationships of acculturation with (a) psychological strain (including: anxiety/depression, and social dysfunction), (b) job satisfaction, and (c) family satisfaction.

Hypothesis 6. Family interfering with work will mediate the relationships of acculturation with (a) psychological strain (including anxiety/depression, and social dysfunction), (b) job satisfaction, and (c) family satisfaction.

\section{Subjective well-being mediating the effect of acculturation on WFC}

(Model B). A number of acculturation studies have demonstrated that acculturation has a direct effect on subjective well-being (e.g., Yoon, Lee, \& Goh, 2008). Furthermore, a small number of work-family researchers have argued that a reverse relationship (as opposed to what is proposed in Hypotheses 2 - 4) may exist between subjective well-being and WFC (e.g., Nohe et al., 2015). Therefore, we also tested an 
WORK-FAMILY CONFLICT, ACCULTURATION, AND WELL-BEING

alternative (Model B), which posits that subjective well-being will mediate the relationship between acculturation and WFC, to compare with Model A.

Through a person's life, stressful events such as moving to an unfamiliar environment might impair his/her psychological health, job satisfaction, and family satisfaction (Leong, 2001). For example, at the early stage of migration, immigrants cannot avoid being subjected to some degree of acculturative stress, feelings of confusion, frustration, and anxiety due to experiences in their new environment (Neuliep, 2014). In the workplace, a lack of intercultural communication skills may lead to interpersonal conflict between immigrant workers and local workers (Amason, Allen, \& Holmes, 1999). In family life, when parent/adolescent or husband/wife fit into the new country at difference paces, conflict between family members may occur (Suárez-Orozco \& Suárez-Orozco, 2010). As such, personal resources could be threatened or actually lost in the process of juggling two cultures if the immigrants are unable to interact effectively with their new environment. Regarding the conservation of resources theory, losing resources is bound to undermine immigrants' subjective well-being. Thus, we proposed:

Hypothesis 7. Acculturation will be negatively related to (a) psychological strain (including: anxiety/depression, and social dysfunction), and positively related to (b) job satisfaction and (c) family satisfaction.

There are arguments suggesting that subjective well-being is likely to influence the experience of work-family conflict (WFC) (Nohe et al., 2015). Based on the conservation of resources theory, Matthews, Wayne, and Ford (2014) suggested that subjective well-being can serve as a personal resource. For example, individuals who experience high levels of job/family satisfaction might perceive that they have a high level of self-efficacy for managing their work/family roles. In the same vein, 
WORK-FAMILY CONFLICT, ACCULTURATION, AND WELL-BEING

people who have a high level of psychological health may perceive that they have sufficient energy to enrich their lives. Accordingly, the gain or loss of personal resources would result in the decreased or increased levels of work-family conflict (e.g., Hobfoll, 2011). Therefore, subjective well-being is likely to have a negative relationship with WFC.

Specifically, the symptom of psychological strain, either anxiety/depression or social dysfunction, is a state of emotional distress which is a result of perceived threat to personal resources (Hussin, 2014). As such, the battle for individuals' resources between work and family could become even severe. Thus, we argued that:

Hypothesis 8. Psychological strain (including: anxiety/depression, and social dysfunction) will be positively related to (a) work interfering with family and (b) family interfering with work.

As mentioned earlier, three perspectives (cross-domain, same-domain, and boundary-permeability perspectives) were examined by testing the relationships between WIF/FIW and job/family satisfaction. Furthermore, Nohe et al. (2015) suggested that those perspectives could also be applied to the reverse relationships of job/family satisfaction with WIF/FIW. Specifically, if family satisfaction (job satisfaction) only significantly impacts WIF (FIW), then the cross-domain perspective will be supported. That is, when individuals suffer low levels of family (job) satisfaction, they would like to utilize more resources to try to increase their family (job) satisfaction, which might be impeded by the demanding work (family), and then WIF (FIW) is likely to happen. However, if family satisfaction (job satisfaction) exerts a significant effect only on FIW (WIF), the same-domain perspective will be supported. The rationale is that when suffering low levels of job (family) satisfaction, individuals are likely to blame work (family) for creating pressure which causes 
WIF(FIW). Finally, if family/job satisfaction significantly influence both WIF and FIW, the boundary-permeability perspective will be evidenced, as permeable work and family role boundaries enable individuals to integrate the domains of work and family (Powell \& Greenhaus, 2012). Taken together, we proposed:

Hypothesis 9. Job satisfaction will be negatively related to (a) work interfering with family and (b) family interfering with work.

Hypothesis 10. Family satisfaction will be negatively related to (a) work interfering with family and (b) family interfering with work.

Regarding social identity theory, failure to fit into the host culture could minimize immigrants' success at the workplace and their sense of family satisfaction, and simultaneously escalate their psychological strain (Lazarova et al., 2010). Moreover, as mentioned earlier, drawing on the conservation of resources theory, lower levels of subjective well-being are likely to intensify people's WFC (Nohe et al., 2015). In support of our argument, research has reported that acculturation is positively related to subjective well-being (Yoon et al., 2008), and subjective wellbeing is negatively associated with WFC (Nohe et al., 2015).

Therefore, given the aforementioned arguments (including Hypotheses 7 - 10), we predicted that subjective well-being will mediate the influence of acculturation on WFC.

Hypothesis 11. (a) Psychological strain (including: anxiety/depression, and social dysfunction), (b) job satisfaction will mediate the relationships between acculturation and work interfering with family.

Hypothesis 12. (a) Psychological strain (including anxiety/depression, and social dysfunction), (b) job satisfaction will mediate the relationships between acculturation and family interfering with work. 


\section{Method}

\section{Sample and Procedure}

An immigrant usually refers to a person who move from one country to settle in another country (Razum, \& Samkange-Zeeb, 2008). According to the definition, our participants were Chinese, born in Mainland China, Hong Kong, Taiwan, Singapore or Malaysia, working at least 15 hours per week, and living with at least one family member ${ }^{1}$ in New Zealand. Data were collected from universities, Chinese companies, Chinese associations and Chinese churches in New Zealand. Initially, we used the snowball sampling technique, and a total of 577 Chinese immigrants participated in the Time 1 (T1) survey. Approximately six months later, these 577 respondents were invited to complete the Time 2 (T2) survey. A total of 264 (response rate $=45.8 \%$ ) participated in the T2 survey. $51.9 \%$ were male, $71.6 \%$ had dependents at home, and $78.4 \%$ held a Bachelor's degree, with $34.1 \%$ also having a higher tertiary qualification. The average age of the sample was 39.77 years $(S D=10.50)$. The average time of residence in New Zealand was 140.23 months, ranging from 9 to 720 months $(S D=82.16)$, and average job tenure was 66.67 months, ranging from 1 to 324 months $(S D=58.05)$.

\section{Measures}

Using Brislin's (1970) method, all survey items were translated into Chinese and then back-translated into English to minimize translation error. The same measures were used at both T1 and T2. The original English version of the questionnaire was firstly translated into Chinese by two linguistics Ph.D. students, and then the Chinese version was translated back into English by three English teachers in China. Another three university lecturers whose native language is English compared the wording equivalence between original and back-translated versions. Finally, we 
WORK-FAMILY CONFLICT, ACCULTURATION, AND WELL-BEING

provided three language versions of questionnaire for potential participants to choose, simplified Chinese, traditional Chinese and English.

Work-family conflict (WFC). Six items were used to assess WFC (Carlson et al., 2000). Three items respectively measured each of WIF $\left(\alpha_{\mathrm{T} 1}=.83 ; \alpha_{\mathrm{T} 2}=.79\right)$, and FIW $\left(\alpha_{\mathrm{T} 1}=.88 ; \alpha_{\mathrm{T} 2}=.90\right)$. Sample items are "Due to all the pressures at work, sometimes when I come home I am too stressed to do the things I enjoy" for WIF, and "Due to stress at home, I am often preoccupied with family matters at work" for FIW. Response options ranged from 1 (Strongly disagree) to 5 (Strongly agree), with a higher score representing more work-family conflict.

Job satisfaction. Three items from Seashore, Lawler, Mirvis, and Cammann (1982) were used to assess job satisfaction $\left(\alpha_{\mathrm{T} 1}=.81 ; \alpha_{\mathrm{T} 2}=.81\right.$, e.g., "In general, I don’t like my job"). Response options ranged from 1 (Strongly disagree) to 7 (Strongly agree), with higher scores indicating greater job satisfaction.

Family satisfaction. Family satisfaction was measured with three items from Edwards and Rothbard (1999) $\left(\alpha_{\mathrm{T} 1}=.95 ; \alpha_{\mathrm{T} 2}=.97\right.$, e.g., "In general, I am satisfied with my family life.”). Response options ranged from 1 (Strongly disagree) to 7 (Strongly agree), with higher scores indicating greater family satisfaction.

Psychological strain. Psychological strain was measured by eight items from the General Health Questionnaire revised by Kalliath et al. (2004). Four items were used to assess social dysfunction, referred to as an individual's self-evaluation of the performance of his/her daily activities and coping ability $\left(\alpha_{\mathrm{T} 1}=.82 ; \alpha_{\mathrm{T} 2}=.78\right.$; e.g., "Been able to face up to my problems"). Four items were used to assess anxiety/depression, referred to as the extent of an individual's anxiety/depression symptoms $\left(\alpha_{\mathrm{T} 1}=.77 ; \alpha_{\mathrm{T} 2}=.83\right.$; e.g., "Been losing confidence in myself"). Response 
options ranged from 1 (Never) to 5 (All the time), with higher scores indicate higher levels of psychological strain.

Acculturation. Fourteen items developed by Gim Chung et al. (2004) were used to assess acculturation $\left(\alpha_{\mathrm{T} 1}=.91 ; \alpha_{\mathrm{T} 2}=.92\right.$; e.g., "How well do I read and write in English?"). Response options ranged from 1 (Not very much) to 5 (Very much), with higher scores representing a greater level of acculturation.

\section{Confirmatory factor analysis}

Before proceeding with hypothesis testing, a series of confirmatory factor analyses (CFA) was conducted using AMOS 23 to confirm the factor structures of the measures. T1 data were firstly used to conduct these analyses. Consequently, WFC was split into two factors: WIF and FIW. Acculturation was initially separated into four factors: language proficiency, cultural knowledge, cultural identity, and food consumption. However, we consider that a single aspect of acculturation per se may not be able to represent acculturation. For example, immigrants could obtain a high level of second-language proficiency in their home country before moving to the new country, but that does not mean that they have acculturated. Therefore, we conducted a higher-order factor analysis for the measure of acculturation, and the model fit was significantly better than the four-factor model. As such, one-factor acculturation was used in this study. Job and family satisfaction were one-factor measures. Psychological strain was divided into two factors: social dysfunction and anxiety/depression.

All instruments achieved an acceptable level of fit (full results are available from the corresponding author). Standardized factor loadings were on average .79 for WIF, .87 for FIW, .61 for acculturation, .76 for job satisfaction, .93 for family satisfaction, .70 for social dysfunction, and .71 for anxiety/depression. We also 
applied the T1 CFA results to T2 data, and all T2 the model fit and factor loadings also achieved an acceptable level (full results are available from the corresponding author). Hence, seven distinct constructs were used in this research: WIF, FIW, acculturation, job satisfaction, family satisfaction, social dysfunction, and anxiety/depression.

\section{Analysis}

As we had two waves of data, Cole and Maxwell (2003) suggested that analysis should include T1 scores for the exogenous variables (predictors), along with T2 scores for the endogenous variables (mediators and outcomes). In order to avoid contamination and inflated causal path estimates, we used T1 mediators and T1 outcomes to control T2 mediators and T2 outcomes respectively (Cole \& Maxwell, 2003). Model A and B were tested using SEM in AMOS 23 to assess the direct effects (Hypotheses 1- 4, and Hypotheses $7-10$ ) and mediating effects (Hypotheses 5 - 6, and Hypotheses 11 - 12). We followed recommendations from Zhao, Lynch, and Chen (2010) that a significant mediation effect requires a significant indirect effect $(a \times b)$, and the significance of indirect effects can be determined by the bootstrapping estimates provided by AMOS. Following the recommendation of Grace and Bollen (2005), unstandardized regression coefficients (B) are presented.

\section{Results}

Table 1 shows descriptive statistics and correlations for the study variables.

\section{INSERT TABLE 1 ABOUT HERE}

\section{Control variables}

Regarding the control variables, some researchers (e.g., Byron, 2005) suggested that demographic variables have little influence on the magnitude of the parameter 
estimates in WFC models. Spector and Brannick (2011) argued that demographic variables do not need to be controlled if they are theoretically unimportant and have little relationship with main variables. In our two mediation models, resident length, education and job tenure had moderate correlations with acculturation (see Table 1). However, all the demographic variables had inconsistent and small correlations with the other variables (see Table 1). Hence, only acculturation was controlled by resident length, education and job tenure while we tested the two mediation tests.

\section{WFC Mediating the Effect of Acculturation on Subjective Well-being (Model A)}

Model A was supported, with overall fit statistics suggesting good model fit: $\chi^{2}(69)=163.98(p=.000), \mathrm{CFI}=0.93, \mathrm{SRMR}=0.07$, and RMSEA $=0.07$ The direct and indirect effects are displayed in Table 2. However, acculturation ${ }_{\mathrm{T} 1}$ had no significant relationship with either $\mathrm{WIF}_{\mathrm{T} 2}$ or $\mathrm{FIW}_{\mathrm{T} 2}$. Therefore, there is no evidence to support Hypotheses 1a and $1 \mathrm{~b}$.

With regard to the tests of WFC predicting subjective well-being, $\mathrm{WIF}_{\mathrm{T} 2}$ was significantly negatively related to job satisfaction $\mathrm{T}_{2}(\mathrm{~B}=-.29, p<.001)$, but positively related to social dysfunction $\mathrm{T}_{\mathrm{T} 2}(\mathrm{~B}=.13, p<.01)$ and to anxiety/depression $\mathrm{T}_{\mathrm{T} 2}(\mathrm{~B}=.21$, $p<.001)$. Similarly, FIW $_{\mathrm{T} 2}$ was significantly negatively related to job satisfaction ${ }_{\mathrm{T} 2}(\mathrm{~B}$ $=-.19, p<.05)$, and to family satisfaction ${ }_{\mathrm{T} 2}(\mathrm{~B}=-.23, p<.001)$, but positively related to social dysfunction $\mathrm{T} 2_{2}(\mathrm{~B}=.19, p<.001)$ and to anxiety/depression ${ }_{\mathrm{T} 2}(\mathrm{~B}=.19, p$ $<.001)$. Therefore, the results suggest that WFC could be regarded as a predictor of subjective well-being in our sample, which lends support for Hypotheses 2, 3, and 4. Furthermore, we found no support for WFC as a mediator in the relationship between acculturation and subjective well-being, inconsistent with Hypotheses 5 and 6 . 
WORK-FAMILY CONFLICT, ACCULTURATION, AND WELL-BEING

\section{Subjective Well-being Mediating the Effect of Acculturation on WFC (Model B)}

Model B was supported, with overall fit statistics suggesting excellent model fit: $\chi^{2}(68)=146.15(p=.000), \mathrm{CFI}=0.94, \mathrm{SRMR}=0.07$, and $\mathrm{RMSEA}=0.07$. The direct and indirect effects are displayed in Table 2. Hypothesis 7 predicted that the levels of acculturation would function as a predictor of Chinese immigrants' subjective well-being. The results shown that acculturation ${ }_{\mathrm{T} 1}$ was negatively associated with social dysfunction $_{\mathrm{T} 2}(\mathrm{~B}=-.10, p<.05)$, and significantly positively associated with job satisfaction $\mathrm{T}_{2}(\mathrm{~B}=.30, p<.01)$. Therefore, Hypotheses $7 \mathrm{a}$ and $7 \mathrm{~b}$ were supported.

With regard to the tests of subjective well-being predicting WFC (Hypotheses 8,9 and 10), social dysfunction ${ }_{\mathrm{T} 2}$ was significantly positively related to both $\mathrm{WIF}_{\mathrm{T} 2}(\mathrm{~B}$ $=.27, p<.001)$ and $\operatorname{FIW}_{\mathrm{T} 2}(\mathrm{~B}=.22, p<.01)$. Anxiety/depression $\mathrm{T}_{2}$ was also significantly positively associated with both $\mathrm{WIF}_{\mathrm{T} 2}(\mathrm{~B}=.25, p<.001)$ and $\mathrm{FIW}_{\mathrm{T} 2}(\mathrm{~B}$ $=.22, p<.001)$. Those results lend support to Hypotheses $8 \mathrm{a}$ and $8 \mathrm{~b}$. Additionally, job satisfaction ${ }_{\mathrm{T} 2}$ was significantly negatively related to $\mathrm{WIF}_{\mathrm{T} 2}(\mathrm{~B}=-.10, p<.01)$, supporting Hypothesis 9a. Furthermore, family satisfaction ${ }_{\mathrm{T} 2}$ was significantly negatively related to $\mathrm{FIW}_{\mathrm{T} 2}(\mathrm{~B}=-.10, p<.01)$, supporting Hypothesis $10 \mathrm{~b}$.

With regard to Hypotheses 11 and 12, social dysfunction ${ }_{\mathrm{T} 2}(\mathrm{~B}=-.03, p<.05)$ and job satisfaction ${ }_{\mathrm{T} 2}(\mathrm{~B}=-.03, p<.05)$ significantly mediated the relationships between acculturation ${ }_{\mathrm{T} 1}$ and $\mathrm{WIF}_{\mathrm{T} 2}$, which supports Hypotheses $11 \mathrm{a}$ and $11 \mathrm{~b}$. Additionally, social dysfunction $_{\mathrm{T} 2}\left((\mathrm{~B}=-.02, p<.05)\right.$ and family satisfaction ${ }_{\mathrm{T} 2}(\mathrm{~B}=$ $-.02, p<.05)$ significantly mediated the relationships between acculturation $\mathrm{T}_{\mathrm{T} 1}$ and FIW $_{\mathrm{T} 2}$, which supports Hypotheses $12 \mathrm{a}$ and $12 \mathrm{c}$. Therefore, those results partially support for subjective well-being as a mediator in the relationship between acculturation and WFC. 
INSERT TABLE 2 ABOUT HERE

\section{Discussion}

In this longitudinal study, we set out to establish mechanisms that link acculturation, WFC, and subjective well-being among Chinese immigrants in New Zealand by testing two theory-based models. Specifically, Model A is that WFC mediates the relationship between acculturation and subjective well-being, while Model B is that subjective well-being mediates the relationship between acculturation and WFC. The two models were presented due to theories that could support either, yet with regard to the work-family experiences of immigrant populations remain unclear. We assessed the direct and indirect effects in both models. The most important findings emerging from our study are: (1) acculturation was directly related to subjective well-being; (2) subjective well-being could function as a mediator of the relationship between acculturation and WFC; (3) there were reciprocal relationships between WFC and subjective well-being; and (4) the same-domain perspective was most supported. Overall, these findings suggest that Model B is relatively better than Model A.

\section{Acculturation Directly Predicting Subjective Well-being}

Our results partially supported a direct relationship between acculturation and subjective well-being. Specifically, acculturation was directly related to job satisfaction and social dysfunction. It appears that the more immigrant workers acculturate into local culture, the more likely they will report higher job satisfaction and psychological health. This could be because when immigrants are highly acculturated, their language proficiency is improved, new social networks are built up, new conflict resolution skills are learned, and they get used to local work norms (e.g., Berry, 2002; Winkelman, 1994). According to the conservation of resources 
WORK-FAMILY CONFLICT, ACCULTURATION, AND WELL-BEING

theory, this new learning could serve to enrich individuals' resource pool (gain spiral) (Hobfoll, 2011; Lazarova et al., 2010), which will then enhance their performance at workplace and their psychological health. However, acculturation was not significantly related to family satisfaction. That may be because acculturation is not directly relevant to their family life, since many Chinese immigrants, at home, tend to maintain their Chinese values, language, and cultural expectations (Shang et al., 2017).

\section{Acculturation Indirectly Predicting WFC}

The relationship between acculturation and WFC appears to be more indirect than direct, since the results failed to confirm the direct relationships between them in Hypotheses 1a and 1b, but supported the mediation relationships in Hypotheses 11a, 11b, 12a and 12c. Specifically, job satisfaction significantly transmitted the influence of acculturation to WIF, and family satisfaction significantly mediated the relationships between acculturation and FIW. We also found that social dysfunction (one type of psychological strain) significantly transmitted the influence of acculturation to both WIF and FIW. The rationale behind those mediating relationships may be that when immigrants acclimatize to the host culture (that is, highly acculturated), the degree of their psychological comfort would increase in the new environment (Lazarova et al., 2010), which could help prompt more personal resources for them (e.g., Hobfoll, 1989; Hobfoll, 2011). As such, their job satisfaction and psychological health are enhanced. The enhanced well-being could serve as new resources, such as family resources (e.g., good family communication, clarity of family role), and work resource (e.g., good interpersonal relationships with colleagues, clarity of work role), that relieve the tension between work and family. 
Therefore, this finding leads us to suggest that acculturation can exert its influence on WFC via job satisfaction and social dysfunction, rather than directly in our samples.

\section{Reciprocal Relationships between WFC and Subjective Well-being}

Our results are consistent with previous research findings, and reveal that there are reciprocal relationships between WFC and subjective well-being (Hypotheses 2, 3, 4, 8, 9a, and 10b). Specifically, individuals who experience high levels of WIF are more likely to indicate decreased psychological health (Hypothesis 2a) and job satisfaction (Hypothesis 3a), while individuals who perceive low levels of subjective well-being tend to report increased WFC (Hypotheses 9a and 10b). Our findings echo the view of Matthews et al. (2014) that subjective well-being is not only a consequence of WFC, but can also serve as an indicator of conflict. Hobfoll's (2011) notion of a loss spiral could provide an explanation for these reciprocal relationships. People who experience WFC may invest more personal resources than usual to meet the demands of work/family roles. Leading to initial resource losses, which could negatively affect their perceived subjective well-being (Matthews et al., 2014).

Because initial resource losses can lead to a loss spiral (Hobfoll, 2011), negative wellbeing may continue to worsen, exacerbating incompatibility and strain between work and family.

\section{The Same-domain Perspective}

This study extends the ongoing debate about whether same-domain, crossdomain, or the boundary-permeability perceptive provides the best fit in work-family models for Chinese immigrants. In Model A, we found that WIF predicted job satisfaction but not family satisfaction, and the influence of FIW was stronger on family satisfaction than on job satisfaction. In (reverse) Model B, job satisfaction primarily influenced WIF (but not FIW), while family satisfaction affected only FIW 
(but not WIF). These results imply that the same-domain perspective is supported in our samples. That is, on the one hand, WIF has significant effects on work-related well-being, and FIW has significant effects on family-related well-being; on the other hand, work-related well-being significantly influences WIF, and family-related wellbeing significantly influences FIW. The reason could be that individuals cognitively tend to appraise the source of the conflict or strain negatively (Shockley \& Singla, 2011). In other words, when conflict or strain occurs, individuals may psychologically attribute blame to the domain which is the source of the conflict or strain (Amstad et al., 2011).

In the context of immigration, this cognitive mechanism could be beneficial to Chinese immigrants for adjusting their work role and family role performance. According to previous research, work (family) resources acquired at work (home) can stimulate Chinese immigrant workers' motivation to participate in their work (family) role in the new host country, which may prompt them to be engaged into the new culture (Lazarova et al., 2010; Llorens, Schaufeli, Bakker, \& Salanova, 2007),

In summary, the direct and indirect hypotheses in Model B were, to a certain degree, supported by our results (12 out 20 hypotheses were supported), while most of the hypotheses in Model A failed to get support from our results (only 7 out 18 hypotheses were supported). It seems that Model B (subjective well-being mediating the relationship between acculturation and WFC) is relatively better than Model A (WFC mediating the relationship between acculturation and subjective well-being).

\section{Theoretical implications}

The present longitudinal study has significant implications for the work-family literature in several ways. First, this is the first longitudinal study to investigate the interactions among acculturation, WFC, and subjective well-being. As previously 
outlined, work-family experiences of immigrants are far more complex, and both Model A and Model B cannot fully capture the reciprocal relationships between WFC and subjective well-being. Nevertheless, our results suggest that the Model B (subjective well-being mediating the relationship between acculturation and WFC) is relatively better than Model A (WFC mediating the relationship between acculturation and subjective well-being). Specifically, acculturation could directly predict the levels of subjective well-being, which then influence the levels of WFC. Therefore, Model B may offer an appropriate framework for future work-family research on immigrant populations.

Our study also contributes to the work-family literature by highlighting the predictive role of acculturation in the work-family experiences of Chinese immigrants. This is important, as acculturation can reshape immigrants' values that will influence their attitudes, expectations and behaviors towards their family and work (Lazarova et al., 2010). The current study provides evidence that acculturation could indirectly predict immigrants' WFC experiences by the mediator of subjective well-being. In previous work-family research, the correlates of WFC are mostly around organizational and family context (Byron, 2005). But immigrants' personal acculturation has received less attention. Therefore, our study broadens the lens that can be used to better understand work-family experiences among immigrant populations by addressing the role of acculturation in WFC models.

Moreover, this study contributes to the recent argument among non-immigrant populations about whether reciprocal relationships between WFC and subjective wellbeing exist. Our results show that WFC and subjective well-being have reciprocal relationships, which is consistent with Matthews et al. (2014) and Nohe et al. (2015). However, there are some limitations of the two studies regarding subjective well- 
being. Matthews et al. (2014) examined only general well-being, while Nohe et al. (2015) investigated only work-related strain. This study simultaneously examined job satisfaction, family satisfaction, and psychological health, which extend previous findings in this area. In doing so, this study extends the argument about the direction of the relationship between WFC and well-being from non-immigrant populations to immigrant populations. Future work-family research might extend this study by testing these reciprocal relationships among other immigrant populations.

Additionally, our results contribute to the ongoing debate among the samedomain, cross-domain, and boundary-permeability perspectives, by testing the relationships of WIF/FIW with job/family satisfaction, and the reverse relationships. We found that the effects between WIF/FIW and job/family satisfaction in both directions are aligned with the same-domain perspective. This finding enriches the work-family literature in two ways. Firstly, we extend the debate largely conducted among non-immigrants to an immigrant population. Secondly, previous research on the debate mainly focused on the same-domain and cross-domain perspectives (e.g., Amstad et al., 2011; Nohe et al., 2015). However, this study brought the boundarypermeability perspective into the debate. Future work-family research might incorporate all three perspectives while investigating the relationships between WIF/FIW and job/family satisfaction, especially among immigrant populations.

\section{Practical implications}

For organizations, it is crucial to understand how work-family conflict affects immigrant employees in diverse working environments (Olson et al., 2013). This study provides insight to aid human resource managers to function in an increasingly diverse workforce. Because our results show that acculturation directly influences immigrants' subjective well-being, one of the most obvious implications is that 
WORK-FAMILY CONFLICT, ACCULTURATION, AND WELL-BEING

managers could facilitate immigrant employees' well-being by fostering acculturation to host work environments. For example, organizations could conduct workshops to comprehensively explain organizational guidelines, policies, and culture for immigrant employees to fit into the new working environments, which could positively contribute to their work-related acculturation. In addition, organizations could provide cultural adjustment training programs for all employees, especially managers, to gain some insight into nuanced cultural differences, which would assist both human resource managers and immigrant employees to operate successfully within a diverse workforce (Meyer, 2014).

Our results illustrate that WIF and job-related outcomes are mutually related (the same-domain perspective, and reciprocal relationships between WFC and subjective well-being). Therefore, organizations should create or continue to improve their family-friendly work policies, incorporating the concerns and demands of immigrants. The policies can serve as tools and resources for immigrant employees to minimize work interfering with their families. For example, policies should allow immigrant workers to have a flexible work schedule, and they can shift their work to stay with their family especially during important ethnic festivals which should be emphasized by human resource managers. Furthermore, relevant training should be provided for managers to understand that subjective well-being has a negative relationship with immigrant employees' WFC, and fostering immigrant employees' subjective well-being should be high on the agenda of human resource managers. For example, managers can assess immigrant employees' well-being in a certain period to know their status of well-being timely and make corresponding actions to address their immediate needs. In doing so, organizational effectiveness could also be enhanced (Amstad et al., 2011). 
Additionally, we found WFC had great effects on subjective well-being. In order to continue to improve the well-being of immigrant employees, managers should also strive to alleviate WFC. For example, managers should pay more attention to the work-related stress caused by acculturation, such as managing the interpersonal conflict at workplace due to the cultural misunderstandings between immigrant employees and local employees (Shang, O'Driscoll, \& Roche, 2016).

\section{Limitations}

Our study has several limitations. First, all the measures were self-reports, which could have some inherent bias in participants' responses (Olson et al., 2013). Our longitudinal data and higher-order statistical approaches (e.g., CFA and SEM) would help reduce this common method bias (Haar, Russo, Suñe, \& Ollier-Malaterre, 2014). Second, although a 6-month gap longitudinal design was applied in the current study, a longitudinal design over decades is needed to provide full insight into the role of acculturation. That is because acculturation progresses at a very slow pace in the first ten years (Taras, Rowney, \& Steel, 2013). Third, it should be noted that value acculturation was not measured in the current study. Acculturation generally occurs not only at the surface level, but also at the core value level (Pooyan, 1984). It would be worthwhile for future work-family researchers to examine the role of value acculturation. Fourth, caution is needed in generalizing our findings, because our study only focused on Chinese immigrants in one country, New Zealand. The current findings may not generalize to immigrants from other cultures, or to Chinese immigrants in countries other than New Zealand. Fifth, the size of immigrant populations in organizations may influence acculturation levels of immigrant employees. However, in our survey, we were not able to identify the size of immigrant populations in the organizations our participants worked for. 
WORK-FAMILY CONFLICT, ACCULTURATION, AND WELL-BEING

\section{Conclusion}

The present longitudinal study compared two theory-based mediation models to illustrate the complex relationships among acculturation, WFC, and subjective well-being in Chinese immigrants in New Zealand. We found that subjective wellbeing mediated the relationship between acculturation and WFC, although there was no direct relationship between acculturation and WFC. Our study provides convincing evidence for the reciprocal relationships between WFC and subjective well-being, as well as the same-domain perspective. Overall, the findings offer a fresh picture of the work-family experiences among immigrant populations, which we hope will encourage work-family researchers to further explore the work-family interface among immigrants, and human resource managers to further improve immigrant employees' well-being. 
WORK-FAMILY CONFLICT, ACCULTURATION, AND WELL-BEING

\section{References}

Allen, T. D., Herst, D. E., Bruck, C. S., \& Sutton, M. (2000). Consequences associated with work-to-family conflict: a review and agenda for future research. Journal of Occupational Health Psychology, 5, 278-308.

Amason, P., Allen, M. W., \& Holmes, S. A. (1999). Social support and acculturative stress in the multicultural workplace. Journal of Applied Communication Research, 27, 310-334.

Amstad, F. T., Meier, L. L., Fasel, U., Elfering, A., \& Semmer, N. K. (2011). A metaanalysis of work-family conflict and various outcomes with a special emphasis on cross-domain versus matching-domain relations. Journal of Occupational Health Psychology, 16, 151-169.

Aycan, Z. (2008). Cross-cultural approaches to work-family conflict. In K. Korabik \& D. Lero (Eds.), Handbook of work-family integration: Research, theory and best practices (pp. 359-371). London: Cambridge Univeristy Press.

Badkar, J., \& Tuya, C. (2010). The Asian workforce: A critical part of New Zealand's current and future labour market. Retrieved from http://www.dol.govt.nz/services/LMI/workforce2020/asian-workforce/asianworkforce.pdf.

Beehr, T. A., \& Glazer, A. (2005). Organizational role stress. In J. Barling, E. K. Kelloway, \& M. R. Frone (Eds.), Handbook of work stress (pp. 7-33). Thousand Oaks, CA: Sage.

Bellavia, F. M., \& Frone, M. R. (2005). Work-family conflict. In J. Barling, E. K. Kelloway, \& M. R. Frone (Eds.), Handbook of work stress (pp. 113-147). Thousand Oak, CA: Sage. 
WORK-FAMILY CONFLICT, ACCULTURATION, AND WELL-BEING

Berry, J. W. (2002). Cross-cultural psychology: Research and applications (2nd ed.). Cambridge, UK: Cambridge University Press.

Billing, T. K., Bhagat, R., Babakus, E., Srivastava, B., Shin, M., \& Brew, F. (2014). Work-family conflict in four national contexts: A closer look at the role of individualism-collectivism. International Journal of Cross Cultural Management, 14, 139-159.

Brislin, R. W. (1970). Back-translation for cross-cultural research. Journal of CrossCultural Psychology, 1, 185-216.

Byron, K. (2005). A meta-analytic review of work-family conflict and its antecedents. Journal of Vocational Behavior, 67, 169-198.

Carlson, D. S., Kacmar, K. M., \& Williams, L. J. (2000). Construction and initial validation of a multidimensional measure of work-family conflict. Journal of Vocational Behavior, 56, 249-276.

Cole, D. A., \& Maxwell, S. E. (2003). Testing mediational models with longitudinal data: questions and tips in the use of structural equation modeling. Journal of abnormal psychology, 112, 558-577.

Cooper, C. L., Cooper, R. D., \& Eaker, L. H. (1988). Lving with stress. London: Penguin.

Dewe, P. J., O'Driscoll, M. P., \& Cooper, C. L. (2010). Coping with work stress: A review and critique. Chichester, UK: John Wiley \& Sons.

Diener, E., Lucas, R. E. \& Oishi, S. (2004). Subjective Well-Being: The Science of Happiness and Life Satisfaction. In C.R. Snyder and S. J. Lopez (eds), Handbook of Positive Psychology (pp. 63-73). Oxford: Oxford University Press. 
WORK-FAMILY CONFLICT, ACCULTURATION, AND WELL-BEING

Edwards, J. R., \& Rothbard, N. P. (1999). Work and family stress and well-being: An examination of person-environment fit in the work and family domains. Organizational Behavior and Human Decision Processes, 77, 85-129.

Edwards, J. R., \& Rothbard, N. P. (2000). Mechanisms linking work and family: Clarifying the relationship between work and family constructs. Academy of Management Review, 25, 178-199.

Fischer, R., Ferreira, M. C., Assmar, E., Redford, P., Harb, C., Glazer, S., . . Kumar, N. (2009). Individualism-collectivism as descriptive norms: Development of a subjective norm approach to culture measurement. Journal of Cross-Cultural Psychology, 40, 187-213.

Ford, M. T., Heinen, B. A., \& Langkamer, K. L. (2007). Work and family satisfaction and conflict: a meta-analysis of cross-domain relations. Journal of Applied Psychology, 92, 57-80.

Francesco, A. M., \& Gold, B. A. (2005). International organizational behavior (2nd ed.). Upper Saddle River, NJ: Pearson Prentice Hall.

Gim Chung, R. H., Kim, B. S., \& Abreu, J. M. (2004). Asian American multidimensional acculturation scale: development, factor analysis, reliability, and validity. Cultural Diversity and Ethnic Minority Psychology, 10, 66-80.

Grace, J. B., \& Bollen, K. A. (2005). Interpreting the results from multiple regression and structural equation models. Bulletin of the Ecological Society of America, $86,283-295$.

Grandey, A. A., \& Cropanzano, R. (1999). The conservation of resources model applied to work-family conflict and strain. Journal of Vocational Behavior, $54,350-370$. 
WORK-FAMILY CONFLICT, ACCULTURATION, AND WELL-BEING

Greenhaus, J., H., \& Beutell, N., J. (1985). Sources of conflict between work and family roles. Academy of Management Review, 10, 76-88.

Greenhaus, J. H., \& Beutell, N. J. (1985). Sources of Conflict between Work and Family Roles. The Academy of Management Review, 10, 76-88.

Grzywacz, J. G., Arcury, T. A., Marín, A., Carrillo, L., Burke, B., Coates, M. L., \& Quandt, S. A. (2007). Work-family conflict: Experiences and health implications among immigrant Latinos. Journal of Applied Psychology, 92, 1119-1130.

Haar, J. M., Russo, M., Suñe, A., \& Ollier-Malaterre, A. (2014). Outcomes of worklife balance on job satisfaction, life satisfaction and mental health: A study across seven cultures. Journal of Vocational Behavior, 85, 361-373.

Hobfoll, S. E. (1989). Conservation of resources: A new attempt at conceptualizing stress. American Psychologist, 44, 513-524.

Hobfoll, S. E. (2011). Conservation of resource caravans and engaged settings. Journal of Occupational and Organizational Psychology, 84, 116-122.

Hofstede, G., Hofstede, G. J., \& Minkov, M. (2010). Cultures and organizations: Software of the mind: Intercultural cooperation and its importance for survival (3rd ed.). New York: McGraw-Hill.

Hussin, R. (2014). Work-family conflict and well-being among employed women in Malaysia: The roles of coping and work-family facilitation. Unpublished doctoral dissertation, University of Waikato, Hamilton, New Zealand.

Judge, T. A., \& Colquitt, J. A. (2004). Organizational justice and stress: the mediating role of work-family conflict. Journal of Applied Psychology, 89, 395-404. 
Kahn, R. L., Wolfe, D. M., Quinn, R. P., Snoek, J. D., \& Rosenthal, R. A. (1964). Organizational stress: Studies in role conflict and ambiguity. New York, NY: Wiley.

Kalliath, T. J., O'Driscoll, M. P., \& Brough, P. (2004). A confirmatory factor analysis of the General Health Questionnaire-12. Stress and Health, 20, 11-20.

Kinnunen, U., Feldt, T., Geurts, S., \& Pulkkinen, L. (2006). Types of work-family interface: Well-being correlates of negative and positive spillover between work and family. Scandinavian journal of psychology, 47, 149-162.

Lambert, E. G., Hogan, N. L., Camp, S. D., \& Ventura, L. A. (2006). The impact of work-family conflict on correctional staff A preliminary study. Criminology and Criminal Justice, 6, 371-387.

Lazarova, M., Westman, M., \& Shaffer, M. A. (2010). Elucidating the positive side of the work-family interface on international assignments: A model of expatriate work and family performance. Academy of Management Review, 35, 93-117.

Leong, F. T. L. (2001). The role of acculturation in the career adjustment of Asian American workers: A test of Leong and Chou's (1994) formulations. Cultural Diversity and Ethnic Minority Psychology, 7, 262-273.

Li, W. W. (2011). Shifting Selves: Home beyond the house - A study of ageing, housing and wellbeing of older Chinese migrants to New Zealand. Unpublished doctoral dissertation, University of Waikato, Hamilton, New Zealand.

Llorens, S., Schaufeli, W., Bakker, A., \& Salanova, M. (2007). Does a positive gain spiral of resources, efficacy beliefs and engagement exist? Computers in human behavior, 23, 825-841. 
WORK-FAMILY CONFLICT, ACCULTURATION, AND WELL-BEING

Lu, L., Gilmour, R., Kao, S.-F., \& Huang, M.-T. (2006). A cross-cultural study of work/family demands, work/family conflict and wellbeing: the Taiwanese vs British. Career Development International, 11, 9-27.

Matthews, R. A., Wayne, J. H., \& Ford, M. T. (2014). A work-family conflict/subjective well-being process model: A test of competing theories of longitudinal effects. Journal of Applied Psychology, 99, 1173-1187.

McDougall, L., \& Drummond, P. D. (2010). Personal resources moderate the relationship between work stress and psychological strain of submariners. Military Psychology, 22, 385-398.

Meyer, E. (2014). The culture map: Breaking through the invisible boundaries of global business. New York: PublicAffairs.

Michel, J. S., Kotrba, L. M., Mitchelson, J. K., Clark, M. A., \& Baltes, B. B. (2011). Antecedents of work-family conflict: A meta-analytic review. Journal of Organizational Behavior, 32, 689-725.

Michel, J. S., Mitchelson, J. K., Kotrba, L. M., LeBreton, J. M., \& Baltes, B. B. (2009). A comparative test of work-family conflict models and critical examination of work-family linkages. Journal of Vocational Behavior, 74, 199-218.

Neuliep, J. W. (2014). Intercultural communication: A contextual approach. Thousand Oaks, Calif: Sage Publications.

Nohe, C., Meier, L. L., Sonntag, K., \& Michel, A. (2015). The chicken or the egg? A meta-analysis of panel studies of the relationship between work-family conflict and strain. Journal of Applied Psychology, 100, 522-536.

Nohe, C., \& Sonntag, K. (2014). Work-family conflict, social support, and turnover intentions: A longitudinal study. Journal of Vocational Behavior, 85, 1-12. 
WORK-FAMILY CONFLICT, ACCULTURATION, AND WELL-BEING

O'Driscoll, M. P., Brough, P., \& Kalliath, T. J. (2004). Work/family conflict, psychological well-being, satisfaction and social support: A longitudinal study in New Zealand. Equal Opportunities International, 23, 36-56.

Odle-Dusseau, H. N., Herleman, H. A., Britt, T. W., Moore, D. D., Castro, C. A., \& McGurk, D. (2013). Family-supportive work environments and psychological strain: A longitudinal test of two theories. Journal of Occupational Health Psychology, 18, 27-36.

Olson, K. J., Huffman, A. H., Leiva, P. I., \& Culbertson, S. S. (2013). Acculturation and Individualism as Predictors of Work-Family Conflict in a Diverse Workforce. Human Resource Management, 52, 741-769.

Pooyan, A. (1984). Acculturation, acculturative stress and their relationship with work and non-work outcomes. Unpublished doctoral dissertation, University of Texas, Dallas, TX.

Powell, G. N., Francesco, A. M., \& Ling, Y. (2009). Toward culture-sensitive theories of the work-family interface. Journal of Organizational Behavior, 30, 597-616.

Powell, G. N., \& Greenhaus, J. H. (2012). When family considerations influence work decisions: Decision-making processes. Journal of Vocational Behavior, $81,322-329$.

Rothbard, N. P., \& Ramarajan, L. (2009). Checking your identities at the door? Positive relationships between nonwork and work identities. In L. M. Roberts \& J. E. Dutton (Eds.), Exploring positive identities and organizations: Building a theoretical and research foundation (pp. 125-148). New York: Routledge.

Seashore, S. E., Lawler, E. E., Mirvis, P., \& Cammann, C. (1982). Observing and measuring organizational change: A guide to field practice. New York: Wiley. 
WORK-FAMILY CONFLICT, ACCULTURATION, AND WELL-BEING

Shang, S., O'Driscoll, P. M., \& Roche, M. (2016, April). Interpersonal conflict, acculturation, and work-to-family conflict among Chinese immigrants. Paper presented at the 31st Annual Conference of the Society for Industrial and Organizational Psychology, Anaheim, CA.

Shang, S., O'Driscoll, P. M., \& Roche, M. (2017). Moderating role of acculturation in a mediation model of work-family conflict among Chinese immigrants in New Zealand. Stress and Health, 33, 55-68.

Shockley, K. M., \& Singla, N. (2011). Reconsidering work-family interactions and satisfaction: A meta-analysis. Journal of Management, 37, 861-886.

Sonderegger, R., \& Barrett, P. M. (2004). Patterns of cultural adjustment among young migrants to Australia. Journal of Child and Family Studies, 13, 341356.

Spector, P. E., \& Brannick, M. T. (2011). Methodological urban legends: The misuse of statistical control variables. Organizational Research Methods, 14, 287-305. Spector, P. E., Cooper, C. L., Poelmans, S., Allen, T. D., O'Driscoll, M., Sanchez, J. I., . . Lu, L. (2004). A cross-national comparative study of work-family stressors, working hours, and well-being: China and Latin America versus the Anglo world. Personnel Psychology, 57, 119-142.

Suárez-Orozco, C., \& Suárez-Orozco, M. M. (2010). The psychosocial experience of immigration. In R. A. LeVine (Ed.), Psychological Anthropology: A Reader on Self in Culture (pp. 329-344). Chichester, UK: Wiley-Blackwell.

Taras, V., Rowney, J., \& Steel, P. (2013). Working-related acculturation: Change in individual work-related cultural values following immigration. The International Journal of Human Resource Management, 24, 130-151. 
WORK-FAMILY CONFLICT, ACCULTURATION, AND WELL-BEING

Wang, Y. (2015). Interpersonal conflict between employees and managers: The Chinese immigrants experiences of acculturation in New Zealand public sector workplaces. Unpublished Master's dissertation, Victoria University of Wellington Wellington, New Zealand.

Winkelman, M. (1994). Cultural shock and adaptation. Journal of Counseling \& Development, 73, 121-126.

Yoon, E., Lee, R. M., \& Goh, M. (2008). Acculturation, social connectedness, and subjective well-being. Cultural Diversity and Ethnic Minority Psychology, 14, 246-255.

Zhao, X., Lynch, J. G., \& Chen, Q. (2010). Reconsidering Baron and Kenny: Myths and truths about mediation analysis. Journal of consumer research, 37, 197206. 


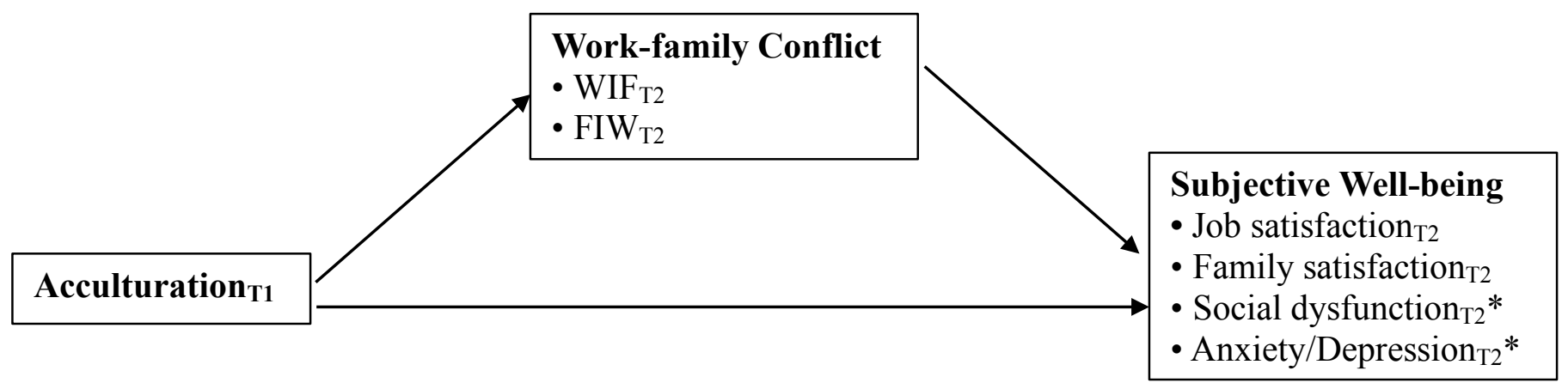

Figure 1. Model A: work-family conflict mediating the relationship between acculturation and subjective well-being. T1 = Time 1; T2 = Time 2; WIF = Strain-based work interference with family; FIW $=$ Strain-based family interference with work.

* Social dysfunction and anxiety/depression are two symptoms of psychological strain.

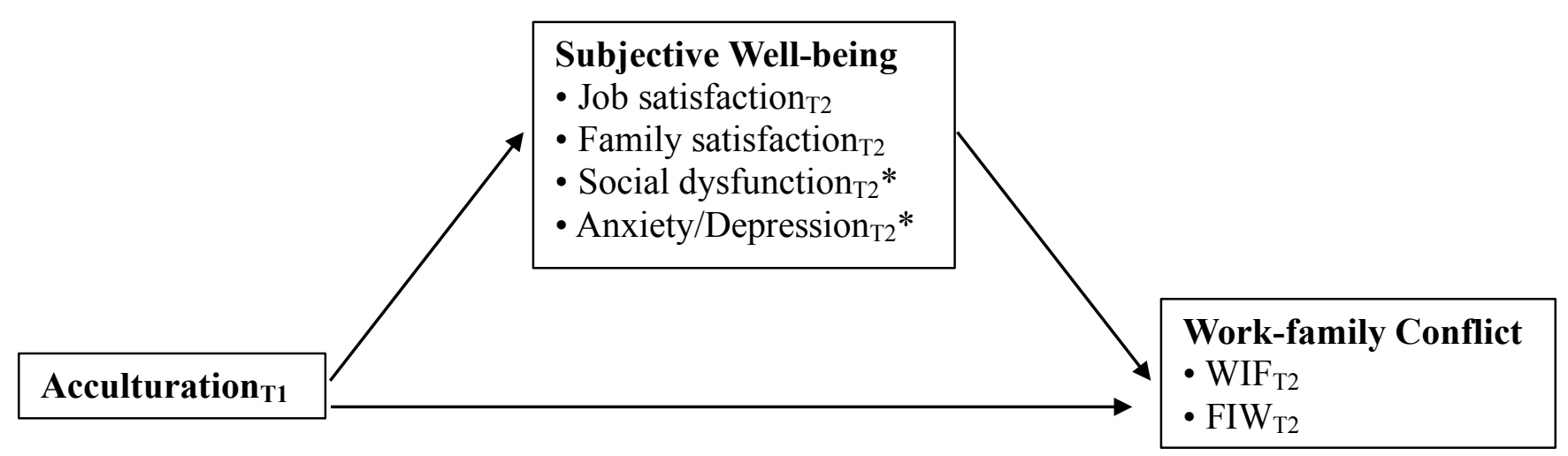

Figure 2. Model B: subjective well-being mediating the relationship between acculturation and workfamily conflict. T1 = Time 1 ; T2 $=$ Time 2 ; WIF $=$ Strain-based work interference with family; FIW $=$ Strain-based family interference with work.

* Social dysfunction and anxiety/depression are two symptoms of psychological strain. 
Table 1. Descriptive Statistics and Correlations for Major Variables $(\mathrm{N}=264)$

\begin{tabular}{|c|c|c|c|c|c|c|c|c|c|c|c|c|c|c|c|}
\hline variables & $M$ & $S D$ & Gende & r Age & $\begin{array}{l}\text { No. of } \\
\text { depends }\end{array}$ & $\begin{array}{l}\text { Resident } \\
\text { length }\end{array}$ & Education & $\begin{array}{l}\text { Job } \\
\text { tenure }\end{array}$ & 1 & 2 & 3 & 4 & 5 & 6 & 7 \\
\hline $1 . \mathrm{WIF}_{\mathrm{T} 2}$ & 2.54 & .81 & $.18^{* *}$ & -.06 & -.02 & .07 & .01 & -.07 & (.79) & & & & & & \\
\hline 2.FIW & 2.26 & .81 & .04 & -.09 & .09 & $-.13^{*}$ & -.05 & -.04 & $.50^{* *}$ & $(.90)$ & & & & & \\
\hline 3. $\mathrm{ACC}_{\mathrm{T} 1}$ & 3.17 & .64 & .07 & -.07 & .05 & $.28^{* *}$ & $.38^{* *}$ & $.22^{* *}$ & -.02 & $-.18^{* *}$ & $(.92)$ & & & & \\
\hline 4.JS $\mathrm{J}_{\mathrm{T} 2}$ & 5.25 & 1.16 & -.07 & .04 & .03 & .00 & $.11^{*}$ & .09 & $-.34^{* *}$ & $-.30^{* *}$ & $.28^{* * *}$ & $(.81)$ & & & \\
\hline 5. $\mathrm{FS}_{\mathrm{T} 2}$ & 5.52 & 1.30 & -.09 & -.09 & -.04 & .06 & $.10^{*}$ & .05 & $-.27^{* *}$ & $-.41^{* *}$ & $.23^{* *}$ & $.38^{* *}$ & $(.97)$ & & \\
\hline 6. $\mathrm{SD}_{\mathrm{T} 2}$ & 2.09 & .61 & .00 & .03 & .04 & .03 & $-.10^{*}$ & -.05 & $.41^{* *}$ & $.43^{* *}$ & $-.21^{* *}$ & $-.47^{* *}$ & $-.51^{* *}$ & $(.78)$ & \\
\hline 7.A/D $/ \mathrm{D}_{\mathrm{T} 2}$ & 2.05 & .71 & $.16^{* *}$ & $-.17^{* *}$ & -.05 & -.02 & .07 & $-.11^{*}$ & $.46^{* *}$ & $.41^{* *}$ & -.06 & $-.32^{* *}$ & $-.38^{* *}$ & $.48^{* *}$ & (.83) \\
\hline
\end{tabular}

Note. WIF = Strain-based work interference with family; FIW = Strain-based family interference with work; ACC = Acculturation; $\mathrm{JS}=$ Job satisfaction; FS = Family satisfaction; $\mathrm{SD}=$ Social dysfunction (one symptom of psychological strain); $\mathrm{A} / \mathrm{D}=$ Anxiety/depression (one symptom of psychological strain); T1 = Time 1; T2 = Time 2. Internal reliabilities are reported along the diagonal in the brackets. $p<.05^{*} ; p<.01 * *$ (One-tailed). 
Table 2. Direct and indirect coefficients in Model A and Model B

\begin{tabular}{|c|c|c|c|}
\hline Mediated Paths in Model A & Indirect effect $(a \times b)$ & Mediated Paths in Model B & Indirect effect $(a \times b)$ \\
\hline $\mathrm{ACC}_{\mathrm{T} 1} \rightarrow \mathrm{WIF}_{\mathrm{T} 2} \rightarrow \mathrm{SD}_{\mathrm{T} 2}$ & $.00 \quad\left(.02 \times .13^{* *}\right)$ & $\mathrm{ACC}_{\mathrm{T} 1} \rightarrow \mathrm{SD}_{\mathrm{T} 2} \rightarrow \mathrm{WIF}_{\mathrm{T} 2}$ & $-.03^{*}\left(-.10^{*} \times .27^{* * *}\right)$ \\
\hline $\mathrm{ACC}_{\mathrm{T} 1} \rightarrow \mathrm{WIF}_{\mathrm{T} 2} \rightarrow \mathrm{A} / \mathrm{D}_{\mathrm{T} 2}$ & $.00 \quad\left(.02 \times .21^{* * *}\right)$ & $\mathrm{ACC}_{\mathrm{T} 1} \rightarrow \mathrm{SD}_{\mathrm{T} 2} \rightarrow \mathrm{FIW}_{\mathrm{T} 2}$ & $-.02^{*}\left(-.10^{*} \times .22^{* *}\right)$ \\
\hline $\mathrm{ACC}_{\mathrm{T} 1} \rightarrow \mathrm{WIF}_{\mathrm{T} 2} \rightarrow \mathrm{JS}_{\mathrm{T} 2}$ & $-.01 \quad\left(.02 \times-.29^{* * *}\right)$ & $\mathrm{ACC}_{\mathrm{T} 1} \rightarrow \mathrm{A} / \mathrm{D}_{\mathrm{T} 2} \rightarrow \mathrm{WIF}_{\mathrm{T} 2}$ & $-.01 \quad\left(-.05 \times .25^{* * *}\right)$ \\
\hline $\mathrm{ACC}_{\mathrm{T} 1} \rightarrow \mathrm{WIF}_{\mathrm{T} 2} \rightarrow \mathrm{FS}_{\mathrm{T} 2}$ & $-.00 \quad(.02 \times-.11)$ & $\mathrm{ACC}_{\mathrm{T} 1} \rightarrow \mathrm{A} / \mathrm{D}_{\mathrm{T} 2} \rightarrow \mathrm{FIW}_{\mathrm{T} 2}$ & $-.01\left(-.05 \times .22^{* * *}\right)$ \\
\hline $\mathrm{ACC}_{\mathrm{T} 1} \rightarrow \mathrm{FIW}_{\mathrm{T} 2} \rightarrow \mathrm{SD}_{\mathrm{T} 2}$ & $-.02\left(-.11 \times .19^{* * *}\right)$ & $\mathrm{ACC}_{\mathrm{T} 1} \rightarrow \mathrm{JS}_{\mathrm{T} 2} \rightarrow \mathrm{WIF}_{\mathrm{T} 2}$ & $-.03^{*}\left(.30^{* *} \times-.10^{* *}\right)$ \\
\hline $\mathrm{ACC}_{\mathrm{T} 1} \rightarrow \mathrm{FIW}_{\mathrm{T} 2} \rightarrow \mathrm{A} / \mathrm{D}_{\mathrm{T} 2}$ & $-.02\left(-.11 \times .19^{* * *}\right)$ & $\mathrm{ACC}_{\mathrm{T} 1} \rightarrow \mathrm{JS}_{\mathrm{T} 2} \rightarrow \mathrm{FIW}_{\mathrm{T} 2}$ & $-.01\left(.30^{* *} \times-.04\right)$ \\
\hline $\mathrm{ACC}_{\mathrm{T} 1} \rightarrow \mathrm{FIW}_{\mathrm{T} 2} \rightarrow \mathrm{JS}_{\mathrm{T} 2}$ & $.02\left(-.11 \times-.19^{*}\right)$ & $\mathrm{ACC}_{\mathrm{T} 1} \rightarrow \mathrm{FS}_{\mathrm{T} 2} \rightarrow \mathrm{WIF}_{\mathrm{T} 2}$ & $.01(.17 \times \quad .00)$ \\
\hline $\mathrm{ACC}_{\mathrm{T} 1} \rightarrow \mathrm{FIW}_{\mathrm{T} 2} \rightarrow \mathrm{FS}_{\mathrm{T} 2}$ & $.04\left(-.11 \times-.33^{* *}\right)$ & $\mathrm{ACC}_{\mathrm{T} 1} \rightarrow \mathrm{FS}_{\mathrm{T} 2} \rightarrow \mathrm{FIW}_{\mathrm{T} 2}$ & $-.02^{*}\left(.17 \times-.10^{* *}\right)$ \\
\hline
\end{tabular}

Note. $a=$ the unstandardized path coefficients of path from predictor to mediator; $b=$ the unstandardized path coefficients of path from mediator to outcome; $\mathrm{T} 1=$ Time $1 ; \mathrm{T} 2=$ Time $2 ; \mathrm{ACC}=$ Acculturation; $\mathrm{WIF}=$ Strain-based work interference with family; FIW $=$ Strain-based family interference with work; JS = Job satisfaction; FS = Family satisfaction; $\mathrm{SD}=$ Social dysfunction (one symptom of psychological strain); A/D = Anxiety/depression (one symptom of psychological strain). $p<.05^{*}, p<.01^{* *}, p<.001^{* * *}$. 
${ }^{1}$ Herein we provide some additional information about how we defined "family". The concept of family may vary in different cultures. In individualistic cultures, people usually refer their family as a nuclear family, while people in collectivistic cultures view their family as an extended family (e.g., Billing et al., 2014). Since this research only focuses on Chinese immigrants who were born in collectivistic cultures, we defined "family" as a social unit consisting of not only spouse and children, but also partner (not married), parents, siblings, or other relatives. Therefore, as long as a Chinese immigrant worker lived with one of above mentioned relatives, he/she was our eligible participant. This information has been indicated at the beginning of our survey. 